\title{
Begin risk assessment for falls in women at 45 , not 65
}

\author{
Katherine J Harmon, ${ }^{1}$ Anne M Hakenewerth, ${ }^{2}$ Anna E Waller, ${ }^{3}$ Amy Ising, ${ }^{3}$ \\ Judith E Tintinalli ${ }^{4}$
}

${ }^{1}$ Department of Epidemiology, University of North Carolina at Chapel Hill, Chapel Hill, North Carolina, USA

${ }^{2}$ Communicable Disease Branch, North Carolina Division of Public Health, North Carolina Department of Health and Human Services, Raleigh, North Carolina, USA

${ }^{3}$ Department of Emergency Medicine, Carolina Center for Health Informatics, University of North Carolina at Chapel Hill, Chapel Hill, North Carolina, USA ${ }^{4}$ Department of Emergency Medicine, The University of North Carolina at Chapel Hill, Chapel Hill, North Carolina, USA

\section{Correspondence to}

Katherine J Harmon,

Department of Epidemiology, Gillings School of Global Public Health, University of North Carolina at Chapel Hill, Chapel Hill, NC 27516, USA; kjharmon@email.unc.edu

Received 10 May 2018 Revised 28 June 2018 Accepted 1 July 2018 Published Online First 23 July 2018

Check for updates

(c) Author(s) (or their employer(s)) 2019. No commercial re-use. See rights and permissions. Published by BMJ.

To cite: Harmon $\mathrm{KJ}$, Hakenewerth AM, Waller AE, et al. Inj Prev

2019;25:184-186

\section{ABSTRACT}

The clinical and epidemiological literature provides guidelines for fall prevention starting at age 65 ; however, the focus on age $\geq 65$ is not evidence based. Therefore, this study examined state-wide North Carolina emergency department visit data to examine the characteristics of falls across the age spectrum, identify the age at which the incidence of fall-related emergency department visits started to increase and determine whether these trends were similar for men and women. We determined that incidence rates of fallrelated emergency department visits began to increase in early middle age, particularly for women. Since fall risk assessment and prevention activities should be initiated prior to an injurious fall, we recommend beginning these activities before age 65 .

\section{INTRODUCTION}

According to the CDC, falls are a top three leading cause of unintentional injury death starting with adults 35 years of age and older. ${ }^{1}$ While the literature is replete with epidemiological reports on the risk assessment, morbidity and mortality of falls in the 'elderly' population, typically defined as $\geq 65$ years of age, few studies have examined falls across the lifespan. Studies typically assess risks and outcomes in those $\geq 65$ years of age, or in those with psychomotor disabilities. ${ }^{2-5}$ Rather than based on scientific evidence, fall injury risk screening appears to be driven primarily by Medicare requirements. ${ }^{6}$ The few studies that have examined fall morbidity across the lifespan have relied on data older than 10 years and/or survey data. ${ }^{78}$ In addition, few studies have identified the age at which the risk of having a fall requiring medical attention begins to increase, and if this risk differs by sex. Furthermore, risk factors of falling, such as type II diabetes and other health comorbidities, are increasing in prevalence among younger individuals. ${ }^{910}$ Therefore, we questioned the appropriateness of fall risk assessment based on the definition of 'elderly' in the USA. In order to better identify the age at which to begin risk assessment activities for fall prevention, we examined state-wide North Carolina (NC) emergency department (ED) visit data.

\section{METHODS}

We conducted a descriptive epidemiological study using ED visit data obtained from NC's state-wide syndromic surveillance system, NC DETECT. During the years 2010-2014, NC DETECT collected ED visit data from all 125 twenty-four-seven, acute care, hospital-affiliated, civilian EDs, capturing over 99\% of all ED visits in the state. ${ }^{11}$

We examined all ED visits from 1 January 2010 to 31 December 2014 that met the CDC's National Center for Injury Prevention and Control's definition of a fall with unintentional intent (E880.0 E886.9, E888). ${ }^{12}$ We assessed fall incidence rates in adults beginning with age 20 , the age which typically defines young adulthood and at which people have maximal muscle strength. ${ }^{12}$ We used the National Center for Health Statistics Bridged Race Population estimates for the denominator in all rate calculations. $^{13}$

We performed analyses using SAS V.9.4 (SAS Institute), calculating frequency tables and unadjusted annual incidence rates with $95 \%$ CIs.

\section{RESULTS}

From 2010 to 2014, NC DETECT collected records for 18.5 million ED visits among adults $>20$ years of age, of which 986024 ED visits (5.3\%) were fall related. Table 1 displays the average annual incidence rate of fall-related ED visits among the NC population stratified by sex and age group. Among adults $>20$ years of age, the average annual incidence rate of fall-related ED visits was 27.4 (95\% CI 27.4 to 27.5 ) ED visits/1000 person-years. The average annual incidence rate was $55 \%$ greater among women (33.0 (95\% CI 32.9 to 33.1) ED visits/1000 person-years) than among men (21.3 (95\% CI 21.3 to 21.4 ) ED visits/1000 person-years).

Throughout the adult lifespan, fall incidence rates in women exceeded those in men (figure 1). For the age group 20-44, fall rates in women were $23 \%$ higher than in men. Starting at age 45, fall rates in women continued to exceed fall rates in men, climbing each year, while rates in men remained stable until after age 65 .

\section{DISCUSSION}

Our study suggests that falls are an important cause of morbidity and mortality in all age groups. However, starting in the decade between ages 45 and 55, the risk of having a fall requiring medical treatment in the ED begins to increase, particularly in women. This contrasts with men, for whom the risk of having a fall requiring treatment in the ED does not begin to increase until around age 65 .

While the incidence rate of fall-related ED visits increases with age, this is just one measure of describing the fall burden among adults. For example, the CDC WISQAR's estimated annual 
Table 1 Frequencies and population-based incidence rates of emergency department visits due to falls stratified by sex and age group among adults $>20$ years of age: North Carolina, 2010-2014

\begin{tabular}{|c|c|c|c|c|c|}
\hline & $\begin{array}{l}20-44 \text { years } \\
(n=319291)\end{array}$ & $\begin{array}{l}45-64 \text { years } \\
(n=276146)\end{array}$ & $\begin{array}{l}65-84 \text { years } \\
(n=266101)\end{array}$ & $\begin{array}{l}\geq 85 \text { years } \\
(n=124486)\end{array}$ & $\begin{array}{l}\text { Total } \\
(n=986024)\end{array}$ \\
\hline \multicolumn{6}{|l|}{ Sex } \\
\hline Women, n (\%) & $176788(55.4)$ & $166257(60.2)$ & $181243(68.1)$ & $97726(76.1)$ & $619014(62.8)$ \\
\hline Men, n (\%) & 142489 (44.6) & 109873 (39.8) & 84836 (31.9) & $29756(23.9)$ & 366954 (37.2) \\
\hline \multirow[t]{2}{*}{ Missing (sex) } & 14 & 16 & 26 & 4 & 56 \\
\hline & \multicolumn{5}{|c|}{ Unadjusted incidence rates per 1000 person-years $(95 \% \mathrm{CI})$} \\
\hline \multicolumn{6}{|l|}{ Sex } \\
\hline Women & 21.5 (21.4 to 21.6$)$ & $24.9(24.8$ to 25.0$)$ & $55.0(54.8$ to 55.3$)$ & 178.4 (177.3 to 179.5$)$ & 33.0 (32.9 to 33.1) \\
\hline Men & $17.6(17.5$ to 17.7$)$ & $17.8(17.7$ to 17.9$)$ & $32.0(31.8$ to 32.3$)$ & $119.0(117.7$ to 120.4$)$ & $21.4(21.3$ to 21.4$)$ \\
\hline Total & 19.5 (19.5 to 19.6$)$ & 21.5 (21.4 to 21.5$)$ & $44.8(44.6$ to 45.0$)$ & $156.0(155.2$ to 157.0$)$ & $27.4(27.4$ to 27.5$)$ \\
\hline
\end{tabular}

average combined medical and work loss costs (in 2010 dollars) for a non-fatal ED visit due to an unintentional fall was $\$ 6831$, $\$ 6504, \$ 4486$ and $\$ 4001$ for adults aged 20-44, 45-64, 65-84 and $\geq 85$ years, respectively. While medical costs increased with age, this increase was offset by reductions in work loss costs. ${ }^{14}$

To date, very little has been reported regarding falls in non-elderly adults, men or women. ${ }^{15}$ Risk assessment and fall prevention efforts focus on older adults; the American Geriatrics Society, British Geriatrics Society and CDC guidelines all advocate fall risk screening in those $\geq 65$ years of age. ${ }^{16}$ Falls are typically assumed to be an affliction of the frail, elderly or those with underlying psychomotor dysfunction. However, many fall-related risk factors, such as lack of physical activity, poor muscle strength, low body mass index, low calcaneal bone mineral density and certain prescription medications, are not limited to the elderly. ${ }^{17}$ Among women, the relative frequency of these risk factors increases after menopause. ${ }^{18}$ Expanding the scope of fall risk injury screening would be the first step to prevent unintentional injury. One potential screening option would be to adapt the popular CDC Stopping Elderly Accidents, Deaths, and Injuries programme to the non-elderly at-risk population. ${ }^{19}$ Information and fall screening tools contained in the primary care electronic health record could be leveraged to screen younger patients in a primary care setting with minimal additional resource utilisation.

\section{Limitations}

NC DETECT ED visit data are collected primarily for hospital administrative purposes. Their use for public health surveillance is a secondary function. However, in our analyses, missing data for key variables such as age, sex and discharge disposition were low $(<5 \%)$.

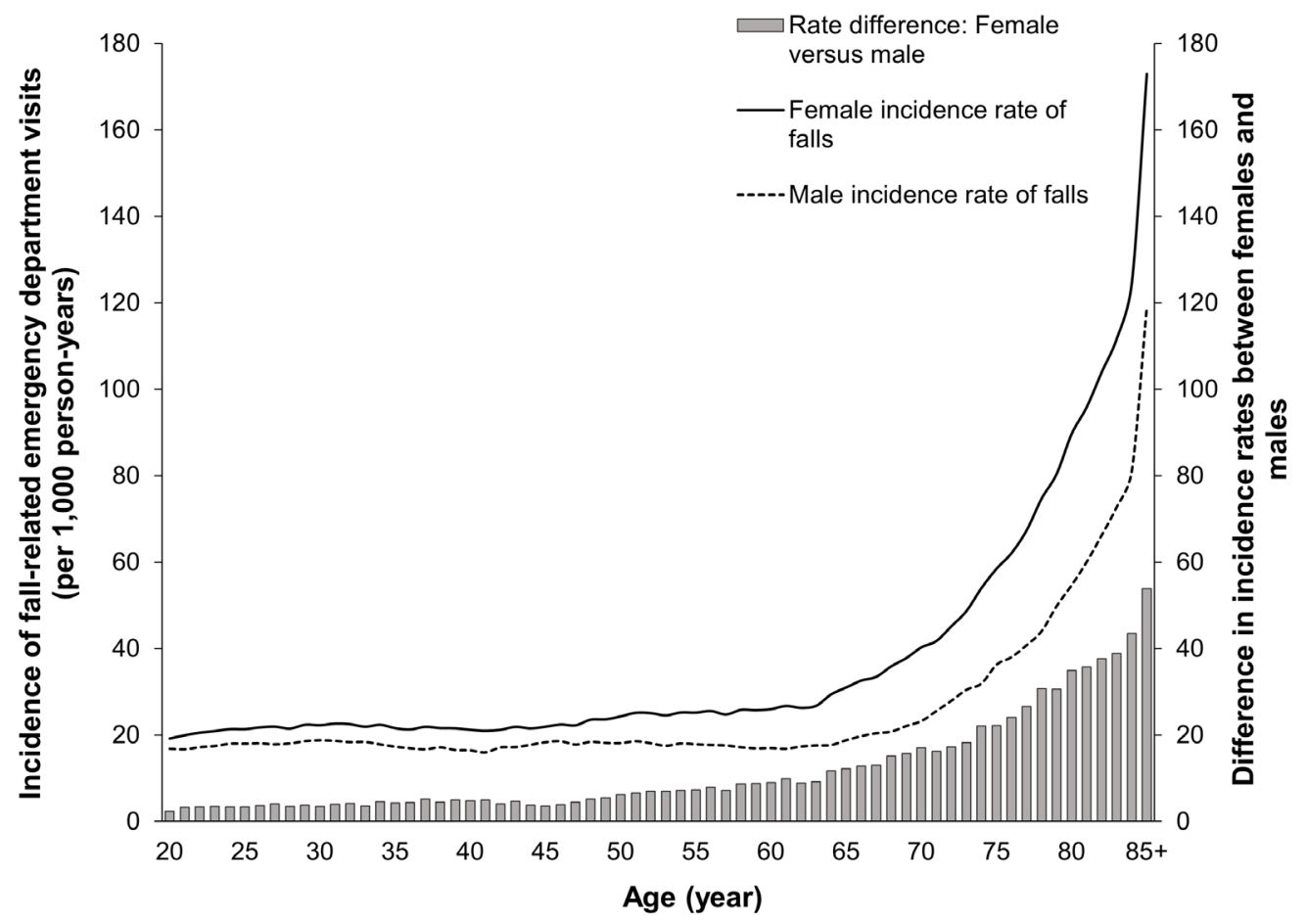

Figure 1 Population-based incidence rates (per 1000 person-years) and rate differences of fall-related emergency department visits among adults $>20$ years of age: North Carolina, 2010-2014. 
A second limitation is generalisability. While the use of statewide population-based data has many inherent benefits, results from this study may not be generalisable to all US jurisdictions. However, similar to NC, most states have a rapidly ageing population and will need to consider the implications for fall prevention. $^{20}$

\section{CONCLUSION}

Fall risk assessment should begin with middle-aged women, so that prevention strategies, including gait, balance and strength training, can be initiated before fall risk accelerates. Our study suggests that waiting until age 60 or 65 to screen for fall risk is too late for women; or alternatively, that screening should begin much earlier, about age 45 for women.

\section{What is already known on the subject}

- Falls are a major cause of injury morbidity and mortality among adults.

- Fall screening and other prevention programmes have been demonstrated to reduce fall morbidity and mortality; however, these activities are rarely initiated in adults under the age of 65 .

\section{What this study adds}

- This study examined the incidence of fall-related emergency department visits across the lifespan.

- Throughout the entire adult lifespan, the incidence of fall-related emergency department visits among women exceeded the rate of fall-related emergency department visits among men.

- The incidence of fall-related emergency department visits started to increase in early middle age among women and somewhat later for men.

Acknowledgements The authors acknowledge Dr Lana Deyneka and Zachary Faigen with the Epidemiology Section, Communicable Disease Branch of the North Carolina Division of Public Health, and Dennis Falls and Clifton Barnett at the Carolina Center for Health Informatics for their assistance in data acquisition and management.

Contributors $\mathrm{AH}, \mathrm{AEW}, \mathrm{Al}$ and JET conceived the work. KJH performed the statistical analyses and drafted the first version of the manuscript. AH, AEW, Al and JET assisted with the literature review, contributed to the interpretation of the results and assisted with manuscript revisions. All authors approved the submitted version of the manuscript.

Funding NC DETECT is a state-wide public health syndromic surveillance system, funded by the NC Division of Public Health (NC DPH) Federal Public Health Emergency Preparedness Grant and managed through collaboration between NC DPH and UNC-CH Department of Emergency Medicine's Carolina Center for Health Informatics.

Disclaimer The NC DETECT Data Oversight Committee does not take responsibility for the scientific validity or accuracy of methodology, results, statistical analyses or conclusions presented.
Competing interests None declared.

Patient consent Not required.

Ethics approval The study was approved by the Institutional Review Board at the University of North Carolina at Chapel Hill. This study was also reviewed and approved by the North Carolina Division of Public Health.

Provenance and peer review Not commissioned; externally peer reviewed.

Data sharing statement The data used in this study are owned by the North Carolina Division of Public Health and are not available for sharing.

\section{REFERENCES}

1 Centers for Disease Control and Prevention, National Center for Injury Prevention and Control. Fatal Injury Data. WISQARS. 2018. https://www.cdc.gov/injury/wisqars/fatal. html (accessed 19 Jun 2018).

2 Bergen G, Stevens MR, Burns ER. Falls and fall injuries among adults aged $\geq 65$ years - United States, 2014. MMWR Morb Mortal Wkly Rep 2016;65:993-8.

3 Burns ER, Stevens JA, Lee R. The direct costs of fatal and non-fatal falls among olde adults-United States. J Safety Res 2016;58:99-103.

4 Kaniewski M, Stevens JA, Parker EM, et al. An introduction to the centers for disease control and prevention's efforts to prevent older adult falls. Front Public Health 2015;3:119.

5 Stevens JA. Falls among older adults-risk factors and prevention strategies. J Safety Res 2005:36:409-11.

6 Phelan EA, Mahoney JE, Voit JC, et al. Assessment and management of fall risk in primary care settings. Med Clin North Am 2015;99:281-93.

7 Mathers LJ, Weiss HB. Incidence and characteristics of fall-related emergency department visits. Acad Emerg Med 1998;5:1064-70.

8 Verma SK, Willetts JL, Corns HL, et al. Falls and Fall-Related Injuries among Community-Dwelling Adults in the United States. PLoS One 2016;11:e0150939.

9 Roman de Mettelinge T, Cambier D, Calders P, et al. Understanding the relationship between type 2 diabetes mellitus and falls in older adults: a prospective cohort study. PLoS One 2013:8:e67055.

10 Zhang N, Yang X, Zhu X, et al. Type 2 diabetes mellitus unawareness, prevalence, trends and risk factors: National Health and Nutrition Examination Survey (NHANES) 1999-2010. J Int Med Res 2017;45:594-609.

11 Carolina Center for Health Informatics. NC DETECT. 2018. http://ncdetect.org/ (accessed 16 Apr 2017).

12 National Center for Injury Prevention and Control. Proposed Matrix of E-code Groupings. Table 1. Recommended framework of E-Code groupings for presenting injury mortality and morbidity data (August 10, 2011).. 2014. https://www.cdc.gov/ injury/wisqars/ecode matrix.html (accessed 20 Apr 2017).

13 National Center for Health Statistics, Centers for Disease Control and Prevention. Bridged-race population estimates, United States July 1st resident population by state, county, age, sex, bridged-race, and Hispanic origin. CDC WONDER Online Database. 2017. http://wonder.cdc.gov/bridged-race-v2015.html (accessed 1 Aug 2017)

14 Centers for Disease Control and Prevention,National Center for Injury Prevention and Control. Nonfatal emergency department treated and released injuries, both sexes, all ages, United States, 2010. WISQARS. 2014. https://wisqars.cdc.gov:8443/costT/Proc essPart1SetupServlet (accessed 3 Apr 2018).

15 Talbot LA, Musiol RJ, Witham EK, et al. Falls in young, middle-aged and older community dwelling adults: perceived cause, environmental factors and injury. BMC Public Health 2005;5:86.

16 Stevens JA, Phelan EA. Development of STEADI: a fall prevention resource for health care providers. Health Promot Pract 2013;14:706-14.

17 Masud T, Morris RO. Epidemiology of falls. Age Ageing 2001;30(Suppl 4):3-7.

18 Geusens P, Autier P, Boonen S, et al. The relationship among history of falls, osteoporosis, and fractures in postmenopausal women. Arch Phys Med Rehabil 2002;83:903-6.

19 Casey CM, Parker EM, Winkler G, et al. Lessons Learned From Implementing CDC's STEADI Falls Prevention Algorithm in Primary Care. Gerontologist 2016;57:787-96.

20 Bureau US. Older People projected to outnumber children [News Release]. Release Number: CB18-41. U. S. Census Bur. 2018. https://www.census.gov/newsroom/pressreleases/2018/cb18-41-population-projections.html (accessed 28 Mar 2018). 